in relation to the general pattern of the national economy. The drive to balance Britain's overseas account by increased exports requires a very large expansion in the volume of engineering exports. Dealing with the difficulties besetting the achievement of this increase in exports, Colonel Leeson said, "The shortage of coal, our only natural resource, is obviously the major cause of our present instability. Of equal significance is the fall in human effort-in its broadest sense of every form of human endeavour. Typical of the causes of this falling off in human effort are the effects of shorter normal hours of work, the longer time spent in education and training coupled with National Service, and the changing structure of the population. These together have brought about shortages in every direction, such as in food, materials, houses, fuel, power, transport and production generally. All these factors in turn have induced alternating notehing up of costs and wages without lasting benefit, unless it be to our foreign competitors; but with lower standards of life for many. The factors are so interlinked in their cumulative effects that it is difficult to know which is cause and which is effect".

There is, of course, a correlation between the activity of the manufacturing industries and the consumption of electricity by the nation, and it is here that the position compares very unfavourably with that of the United States, where the electrical power used per worker is nearly $2 \frac{1}{2}$ times that in Britain. The urgent need for the installation of more generating plant is, of course, only too evident in the load shedding which has become customary in recent years. The attainment in Britain of a yearly rate of plant installation of $2,000 \mathrm{MW}$. is imperative, and a capital investment policy covering this rate of installation is an inescapable economic necessity.

The four basic needs for economic recovery and development in Great Britain are, in Colonel Leeson's opinion, more human effort (that is, more man-hours of work); greater production of the basic commodities such as food, coal, metals, chemicals and other essential materials; more fuel and power for industry and the home; and more capital (that is, greater savings by government, industry and in dividuals). "We are facing," he said, "a choice and a challenge. Are we, as individuals and a nation, content to accept with complacency the relentless trend of current affairs towards lower standards of living, or alternatively, do we take up the challenge this represents, and by courage and the exertion of more strenuous individual effort on things that really matter, change the trend towards recovery and better times?"

A considerable part of the address was devoted to reviewing the growth of employment in the electrical industry in its various branches, and Colonel Leeson gave interesting data on the distribution of professional engineers as represented by membership of the Institution of Electrical Engineers in the major subdivisions of the industry. The total number of people employed in the three main branches of the industry, namely, manufacture, electricity supply and electrical contracting, was, in 1951 , nearly 846,000 . Roughly 70 per cent of this total were employed in manufacture, 22 per cent in supply, and the remaining 8 per cent in contracting. The membership of the Institution of Electrical Engineers, exclusive of students, numbers 31,000 , and an analysis of the percentage of this membership by occupation is as follows: manufacture, 29.8 ; government services, consulting engineers and others, 22.6; electricity supply, $20 \cdot 6$; communications, 10.0 ; research, education and training, 9.9; and installation and maintenance, $7 \cdot 1$. 18 per cent of the Institution's members are serving overseas.

The education and training of all classes of personnel in the industry are, in these days, matters of exceptional importance. The direct interest of the Institution of Electrical Engineers is by its charter limited to the professional engineer; but the Institution does concern itself with the improvement of facilities for technicians and craftsmen, and it co-operates with the British Electrical and Allied Manufacturers' Association and the Radio Industries Council to that end. Colonel Leeson emphasized the close partnership in which industry, technical colleges and universities are associated in this matter of the education and training of engineers, and he urged the recognition, in relation to professional engineers, of valuable features in industry-based 'sandwich' and part-time courses which are complementary to the full-time courses of universities and technical colleges.

The problem of the needed expansion of higher technological education can, in Colonel Leeson's opinion, best be tackled by the selection, on a regional basis, of a few of the existing major technical colleges for expansion and development. These should enjoy academic freedom under a self-governing representative administration and be free from any direct control by the local education authority. "The first essential to this objective is the setting up of a small body (including a few men of high academic and professional status) under the ægis of the Government with the necessary finance and authority to select and guide the chosen colleges in consultation with professional bodies, learned societies, and industry. It would be the duty of every section of the industry to provide facilities for additional and improved training matched to the higher standard of education-a duty rich in its own economic reward."

\section{PLASTICITY OF MATERIALS}

CONFERENCE on plasticity, arranged by the British Society of Rheology, was held in the University of Southampton during September 25-27.

The diverse nature of the problems encountered in flow technology, problems which still lack a fundamental treatment, was strongly evidenced in the discussions which arose on the papers presented. In spite of their diversity, however, it is remarkable how many of these problems derive from the basic problem of test instrumentation. The momentum of rheological inquiry is still sustained, in the main, by those immediately concerned with the behaviour of real commercial materials, working with instruments designed to give some rapid index from which the relevant property can be deduced. These instruments have been evolved in turn from those developed in more fundamental laboratories where the properties of plastic materials made classical viscometry meaningless. This necessary departure in experimental design was, unfortunately, not accompanied by an equivalent development in theoretical treatment, and the situation has become gradually worse as instruments involving more complex stress-systems have been produced on grounds of general utility. The whole line of inquiry, from that of pure research on simple systems and idealized models to that of the actual behaviour of industrial products under 
conditions of use, is one which can profit from the experience of those working on other parts of the line. Disagreement still exists, often on quite basic concepts; but the general process of unification, by theory and experiment, continues.

Instrument design, the difficulties of assessing standards, reconciliation of the results of different test methods-such questions as these are of primary concern to the applied rheologist. Dr. J. R. Scott (British Rubber Manufacturers' Research Association) made it plain that no single plastimeter can meet all the requirements of the rubber industry. Either, as in the rotation-type, the shear-rate is limited, and problems of slip at the containing surfaces arise; or else, as in the Williams press-type, while simple repetitive testing can give reproducible results, the system does not appear to be one which can assist the more fundamental approach to the subject. This problem of widening the scope of industrial instruments has been faced by Mr. G. E. Bessey and Mr. K. A. Lammiman (British Whiting Federation Research Council), who described an apparatus, ingeniously adapted to a lathe bed, which can test at constant rates of extension or compression, recording load and extension on a drum. The grip problem in the extension tests is overcome by extending a specially formed closed loop of the material. The machine can also be adapted for rotation tests, recording the stress against the rate of shear, and can handle material of a wide consistency. The results are of striking reproducibility-a rare quality in plastic testing.

Data derived from such instruments are still difficult to relate significantly to other measured quantities. This aspect of interpretation of data was treated by Mr. F. B. Atkinson ( $B X$-Plastics, Ltd.), mainly in relation to extrusion and the problem of errors of boundary condition. The simple assumptions of extrusion analysis (those applicable to viscometers using Newtonian liquids at low rates) can all be violated, and these effects, together with the temperature gradients that arise, lead to unusual flow phenomena. The flow curves are difficult to treat theoretically; but a basis for such a treatment-and a general equation--was proposed, and this could be reconciled with an examination of the problem in terms of dynamic similarity. Such treatments are often open to criticism on a priori mathematical grounds, but any approach which advances the design of the processing stages will be of positive value to the plastics industries.

Interpretation, then, has its difficulties ; and if an applied laboratory device can reproduce the practical conditions to such a degree that similarity can be claimed, then one stage of interpretation is directly bridged, and the problem is reduced to a true model. This, as an aspect again of rheological instrument problems, was exemplified in a paper by Dr. G. G. Meyerhof (Building Research Station, Garston), whose investigations into the behaviour of clay blocks when compressed between plates of various shape are direct analogies of the building problems of structures where the foundations (or footings) form the upper plate, and the surface of the bed below the clay forms the lower. The yield pressure of such blocks increases rapidly with the adhesion of the material to the plates, and also with decreasing block-thickness. The results are in accord with the theoretical estimates of the yield pressure, and with the assumed mechanism of failure. The unusual occurrence of a gas-holder breaking its back enabled a field investigation to be carried out, and, when the formation of the bed below the clay was traced, the results (treated according to the foregoing theory) provided $a$ stress distribution which beautifully accounted for the result of this impressive large-scale experiment. Mr. P. Mason (Building Research Station, Garston) provided further evidence of progress in establishing the behaviour of building materials. A compression test, of a type originally suggested by Roller, was applied to various plaster mixes, and the extraction of one index-namely, the slope of the experimental line (a log-log plot of empirical quantities which approximate to stress and strain)-provided a grading the sequence of which agreed exactly with that which field-workers, on the basis of experience, accorded to the materials.

A more fundamental instrument-technique was described by Dr. W. W. Barkas and Mr. G. N. Christensen (Faculty of Technology, University of Manchester). This has been developed for a study of the behaviour of wood fibre - water assemblies, similar to those used in the manufacture of paper. These assemblies are formed as small cylinders, placed on a sintered-glass plate and connected by wet contact to one arm of a manometer. Changes in the manometer pressure effectively vary the hydrostatic pressure applied to the assembly, and hence stress - strain studies may be made. As the stiffness of the fibres, and the size of the capillaries in such an assembly, effectively control the type of paper produced in the industrial processes, such results have direct applied importance.

Some problems arising in the choice of materials for aircraft purposes were discussed by Dr. E. W. J. Mardles (Royal Aircraft Establishment, Farnborough). Temperature specifications for such materials as greases are severe, a working range being demanded from conditions of high-altitude cold to those of local engine heat. The required properties of lubricants may be masked by effects which are functions of the instrument-surface tension effects, for example, giving rise to an apparent plasticity. The properties of certain gels are also of importance in aircraft research (cellulose acetate, for example), and the time-dependent properties of such materials were surveyed.

The conference opened with two papers concerned with the fundamental interpretation of plastic flow phenomena. Dr. A. J. Kennedy (Royal Institution, London) reviewed the experimental information available on the mechanisms involved in the creep of polycrystalline metals, and, taking such evidence together with that provided by a wide range of non-metallic materials characterized by a strengthweakness structure (long-chain compounds; mixes and aggregates of various kinds), suggested that the phenomenon of transient creep is an outcome of fairly simple statistical considerations, resulting in parabolæ with time powers which fall very closely about that of the Andrade one-third power. The behaviour of a macroscopic mechanical model was reported : this approximates to the kind of curve exhibited by practical materials. Translation into physical terms is difficult, but the physics of a system which would fulfil the requirements was outlined, and this has interesting analogies with the question of the representation of voters in a two-party electoral system.

Mr. A. Graham (National Gas Turbine Establishment) approached the representation of creep data from the same general point of view, namely, that the striking fact emerging from plasticity results is 
that different materials behave so similarly. Using observations on a heat-resistant alloy at high temperatures, attempts were made to find an equation capable of general application. By a process of trial and error, an equation was developed from those of Nutting and Boltzmann which can be shown to be a special case of the fractional differential equation of Scott-Blair. This equation is capable of successfully embodying the four variables-strain, stress, time and temperature-and is able to fit the various types of creep curve encountered. It is true that several constants may be involved in the more complex cases, but this is defended on the grounds that mechanisms must certainly be multiple and complex, and particularly so in the case of metals.

\section{A. J. KENNEDY}

\section{BRITISH ELECTRONIC INSTRUMENTS IN RESEARCH AND INDUSTRY}

$\mathrm{D}$ URING the period September 2-5 the Scientific Instrument Manufacturers' Association of Great Britain held, in London, an exhibition of electronic instruments, and associated with this was a symposium of papers describing the application of such instruments in research and in industry. This was the fourth such gathering in a series which began in 1948 , the previous exhibition being in 1950 , and it is now proposed to hold future symposia and exhibitions biennially.

The papers read at the symposium covered a wide field of instrumentation. At the first session a description was given of electronic control systems for large astronomical telescopes. After a discussion of the factors leading to the requirement of very accurate control of 'rate' in drives for such telescopes, there followed a review of techniques used up to the present time for achieving this purpose, culminating in the present-day forms of electronic control. A modern requirement is the ability to introduce small variations of rate, and to this end use has been made of very stable resistance-capacity tuned oscillators, either as the actual source of a reference frequency or as the means of introducing some frequency variation of a crystal-controlled source. Reference was also made to a 'photographic zenith tube', shortly to be installed in Great Britain, which will provide a new standard of absolute time determination.

An account was given at the next session of the development of resistive elements and wave-guide attenuators from a semi-conducting ceramic. In contrast to the majority of semi-conductors, pure zinc oxide has a temperature coefficient of resistivity which can be controlled between high positive and negative values; the addition of titanium dioxide makes it possible to achieve this control with commercially available materials, and to control the value of the resistivity. Small resistors, up to ten thousand ohms, and having tolerances and stability similar to grade- $B$ carbon-composition resistors, have been made, and these may be used with surface temperatures up to $200^{\circ} \mathrm{C}$. The material has proved to be very satisfactory for the manufacture of dummy loads to fit in metal wave-guides, as it is unaffected by rapid changes of temperature; these loads absorb microwave energy strongly and also provide a good impedance match in the wave-guide.
Research and development based on precise methods of measurement are responsible in a large degree for the progress upon which the electrical industry depends. Among other topics discussed at later sessions of the symposium were electronics in strain measurement, and electronic measurement and control for industry. In the field of strain measurement, such features as multi-channel strain-display equipment, high-speed self-balancing strain bridges, load cells, load indicators and torque meters were dealt with.

The use of ultrasonic vibrations in many diverse applications has been made possible by the development of electronic methods for the generation of such vibrations, and the final paper of the symposium was concerned with this subject. The applications for industrial purposes cover processes of emulsification and the production of finely divided suspensions ; in these processes the action required is that of the dispersion of one material in another. The same principle is involved in the action of cleaning, and the use of ultrasonic techniques has been proposed both for scouring textiles and for the removal of foreign matter from solid bodies. All these effects depend upon the phenomenon of cavitation, which also makes possible the tinning of aluminium by a method involving the use of vibrations of ultrasonic frequency. Other metallurgical applications include the degassing of melts and grain refinement. Most chemical effects occur at relatively slow reactionrates, but ultrasonic depolymerization has been widely studied : in the biological field micro-organisms have been destroyed, and claims of striking therapeutic results have been made. It appears, however, that there still remains some doubt about the practical usefulness of some of these applications, particularly in cases where high intensities of ultrasonic energy are necessary.

Many different kinds of instruments were to be seen in the exhibition which accompanied the symposium. There were examples of improved design in instruments of various types shown on earlier occasions : instruments for the accurate measurement of power, voltage, current and resistance, and also several items of equipment-signal generators, valve testers, impedance bridges, $Q$-meters-which are now the indispensable tools of the radio engineer. In addition, examples were shown of relatively new developments.

The use of direct-writing instruments for recording variable electrical quantities has until recently been confined to cases in which the rate of change was comparatively small, and direct recording was not possible when frequency components exceeding a few cycles per second occurred, the only recourse then being to photographic recording with Duddell or cathode-ray oscillographs. A new recorder has now been developed which has a moving-coil element so efficient that it may be driven by a simple valve amplifier, but which yet has sufficient restoring torque to deflect a stylus across the paper record in as little as $2.5 \mathrm{msec}$. It is thus now possible to obtain records of high-speed phenomena directly in a dry and permanent form. The suspension of the recorder is of a stiffness which makes the instrument robust enough for use in aircraft or vehicles.

With the increasing demands for maximum efficiency in temperature measurement, cold-(thermo) junction temperature control has become a factor of major importance. A new, mains-operated thermostat has been designed which overcomes the diffi- 